\title{
Breaker bar morphodynamics under erosive and accretive wave conditions in large-scale experiments
}

\author{
Sonja Eichentopf ${ }^{\mathrm{a}, *}$, Iván Cáceres ${ }^{\mathrm{b}}$, José M. Alsina ${ }^{\mathrm{a}}$ \\ ${ }^{a}$ Fluid Mechanics Section, Department of Civil and Environmental Engineering, Imperial \\ College London, South Kensington Campus, SW7 2AZ, UK \\ ${ }^{b}$ Laboratori d'Enginyeria Marítima, Universitat Politècnica de Catalunya, 08034 \\ Barcelona, Spain
}

\begin{abstract}
Differences between breaker bar evolution under high energy (erosive) and subsequent mild energy (accretive) wave conditions are studied based on three data sets from large-scale morphodynamic experiments. Under erosive wave conditions, a clear linear relationship between the height and the cross-shore location of the breaker bar is observed. The similar cross-shore shape of the sediment transport magnitudes underlines the similarity of the bar evolution under erosive wave conditions. Under the subsequent accretive wave conditions, two major evolution patterns are observed during onshore migration (decaying or non-decaying breaker bar). In the presented data, the feedback between the wave conditions and the beach morphology determines if a bar decays during onshore migration. This feedback involves that the wave breaking location depends on the morphology and the wave conditions resulting in differences in sediment transport patterns between the
\end{abstract}

\footnotetext{
*Corresponding author. Tel.: +44 (0)207 5945462

Email addresses: sonja.eichentopf16@imperial.ac.uk (Sonja Eichentopf), i.caceres@upc.edu (Iván Cáceres), j.alsina@imperial.ac.uk (José M. Alsina)
} 
two types of onshore bar migration. A comparison against numerous other experimental beach profile data sets strongly supports the linear relationship between bar height and bar location under erosive wave conditions. For accretive wave conditions, the number of comparable data sets is very limited. The comparison underlines that breaker bar evolution under accretive wave conditions cannot be condensed to a single pattern as under erosive wave conditions.

Keywords: morphodynamic experiments, breaker bar, beach morphology, erosive wave conditions, accretive wave conditions, sediment transport

\section{Introduction}

The feedback between breaker bars and wave conditions is an important expression of morphodynamic processes at beaches. High energy wave conditions result in beach erosion, bar generation and offshore bar migration which is mainly attributed to the feedback between breaking induced under-

tow and the bar $[1,2]$. In contrast, mild energy wave conditions are generally recognised to result in accretive sediment transport and onshore bar migration. However, beach profile response to accretive wave conditions is less well studied and this severely influences the skill of numerical models resulting in far less accurate morphological predictions for accretive, compared to erosive, wave conditions [3].

Prior studies on onshore bar migration have focussed on simulating the bar migration under mild energy conditions and on investigating the physical forcing factors behind it. Specific physics that have been implemented in models to simulate onshore bar migration are acceleration skewness [2] 
and the joint action of velocity and acceleration skewness [4] in energeticstype models, second-order nonlinear sediment advection (Stokes drift) in an eddy-diffusive boundary layer model [5] or sediment-induced buoyancy effects in a nearbed turbulence model [6]. Hsu et al. [7] found that models based on different assumptions (wave resolving boundary layer streaming; energetics-type model with acceleration skewness) had similar profile prediction skills indicating that the governing mechanisms for sediment transport cannot be determined based on the simulation of the one observed onshore bar migration event.

Dubarbier et al. [8] highlighted the importance of the undertow-induced as well as the acceleration skewness-induced sediment transport component for shallow water bar evolution. However, calibration parameters in the model had to be determined for each field site and campaign showing that site- and wave-condition-specific adjustment of model coefficients is required.

While most studies focussed on the bar migration direction and its representation by models $[7,8,9]$, less work has been done on the short-term changes of the bar itself during its migration. Houser and Greenwood [10] observed an intertidal bar (swash bar) which initially decreased and then increased its height during onshore migration. However, intertidal bar morphodynamics are strongly influenced by tidal changes [11] and therefore, the processes are not directly comparable to breaker bars.

For moderate and high energy wave conditions, the cross-shore location of breaker bars has been shown to be strongly linked to the wave breaking location [12,13]. This strong link between bar location and breaking location has motivated several parametric models. Within these models, the bar 
strives towards an equilibrium state and continuously responds to variations in the wave breaking location. For example, Plant et al. [14] reproduced interannual bar behaviour forced by variations in the incident wave energy and breaking location. More recently, Mariño-Tapia et al. [15] investigated sediment transport patterns associated to the presence of bars. Based on near-bed velocity moments, which were normalised by the local energy level, they developed a field transport parameterisation which depended mainly on the wave breaking location. This parameterisation was capable of reproducing the observed cross-shore bar location over a 77 day period with rapid offshore bar migration in response to individual storms and weak onshore bar migration during mild energy conditions.

Because of the strong influence of high energy wave conditions on beaches with direct effects for human activities at coasts [16], research approaches have largely focussed on beach profile evolution during high energy conditions, i. e. storm events. Recently, increasing attention has also been paid to the impact of storm sequences, which are alternating periods of beach erosion and beach recovery (accretion) in close succession, instead of studying single storm events [e.g. 17, 18, 19, 20]. For storm sequences, knowledge about beach profile evolution under both erosive and accretive wave conditions is essential. However, most studies only focussed on the erosive impact of storm sequences and did not consider beach recovery phases [e. g. 17, 20].

This again shows that beach profile evolution, including the previously addressed breaker bar dynamics, under accretive wave conditions is far less studied than under erosive wave conditions. However, accretive wave conditions are essential to understand the long-term beach morphodynamics 
and the resilience of beaches. The present work considers the beach profile evolution under accretive wave conditions. The evolution of breaker bars is studied based on three large-scale morphodynamic data sets which have not been combined in this way before. The breaker bar evolution is compared with further data from large-scale experimental data. This allows new insights into breaker bar evolution under different wave climates and beach conditions. A parameterisation is suggested for beach profile evolution under high energy conditions. Influencing factors for beach profile evolution under both erosive and accretive wave conditions are discussed. Sections 2 and 3 outline the setup of the experiments and the methodology for the data analysis, respectively. In section 4 the results of the profile, sediment transport and the hydrodynamic analysis are presented. A discussion of the results and conclusions follow in section 5 and 6 , respectively.

\section{Experimental setup}

The data in this study were obtained within the SANDS and WISE IV EU funded HYDRALAB projects at the Canal d'Investigació i Experimentació Marítima (CIEM) at the Universitat Politècnica de Catalunya (UPC) in Barcelona, Spain. The experimental setup of SANDS in Barcelona was de-

scribed in detail by e.g. Alsina and Cáceres [21]; detailed information on the WISE IV project can be found in a recent work by Sánchez-Arcilla and Cáceres [22]. Since this work focusses on a comparison between the data sets under erosive and accretive wave conditions, this section points out major similarities and differences in the experimental setup. 


\subsection{Wave flume and instrumentation}

The CIEM is a large-scale wave flume of $100 \mathrm{~m}$ length, $3 \mathrm{~m}$ width and $4.5 \mathrm{~m}$ depth with a working water depth of $2.47 \mathrm{~m}$ and $2.5 \mathrm{~m}$ in SANDS and WISE IV, respectively. Waves are generated by means of a hydraulic wave paddle which is installed at the end of the deep water in the wave flume. Well-sorted, commercial sand with a narrow grain size distribution $\left(d_{50}=0.25 \mathrm{~mm}, d_{10}=0.154 \mathrm{~mm}, d_{90}=0.372 \mathrm{~mm}\right.$, measured sediment fall velocity of $w_{s}=0.034 \mathrm{~m} / \mathrm{s}$ ) was used to create a handmade initial beach profile. The active part of the initial beach profile has a slope of 1/15.

The coordinate system used in this study has its origin at the shoreline of the initial beach profile. The $x$-coordinate is the horizontal coordinate, pointing negative towards the wave paddle and positive towards the emerged part of the beach. The $z$-coordinate is vertically directed and points negative towards the bottom of the wave flume and positive out of the water (see figure 1 in section 3$)$.

In the CIEM, a wide range of data is acquired during the experiments. The profile evolution is measured by means of a mechanical profiler which moves along a central line of the flume. The profiler has an estimated vertical accuracy of $\Delta z_{m}=10 \mathrm{~mm}$ [23] which is noticeably precise considering the large dimensions of the wave flume. Beach profile data were obtained approximately every $30 \mathrm{~min}$ in WISE IV and at varied time intervals in SANDS (average time intervals of $115 \mathrm{~min}$ ).

Hydrodynamic data were obtained over ca. 30 min tests in both SANDS and WISE IV. Acoustic Wave Gauges (AWG), Resistive Wave Gauges (WG) and Pore Pressure Transducers (PPT; only applied in WISE IV) were thor- 
oughly placed along the flume to measure the water surface elevation in the deep part of the flume as well as in the surf and swash zone. Data on the three-dimensional velocity field were acquired by means of Acoustic Doppler Velocimeters (ADV) in the inner surf and swash zone (SANDS) and in the surf and partially the shoaling zone (WISE IV). The minimum ADV elevation above the bed was $0.05 \mathrm{~m}$ but in most of the cases measurements were taken between $0.07 \mathrm{~m}$ and $0.24 \mathrm{~m}$ above the bed. The wave boundary layer thickness is estimated to be of the order of 0.01-0.02 $\mathrm{m}$ [24] and hence, all ADV measurements were obtained above the wave boundary layer. Suspended sediment concentration were measured using Optical Backscatter Sensors (OBS) co-located with ADVs.

\subsection{Test conditions}

Starting from the initial 1/15 sloped beach profile, a test series of erosive wave conditions followed by a test series of accretive wave conditions was performed. In WISE IV this procedure was carried out two times, i. e. after the first erosive and accretive test series, the beach profile was reshaped to its initial slope and a second test series of erosive and subsequent accretive wave conditions was run. Therefore, we will refer to WISE IV as two experiments: WISE 1 comprising the first erosive and its subsequent accretive test series and WISE 2 consisting of the second erosive and its subsequent accretive test series. Specifications on the significant wave height $H_{s}$, the wave period $T_{p}$, the dimensionless sediment fall velocity $\Omega=H_{s} /\left(T_{p} \cdot w_{s}\right)$ and the duration of the wave conditions for SANDS, WISE 1 and WISE 2 are summarised in table 1. It can be noted that in WISE 1 and WISE 2 the erosive wave conditions as well as the erosive experimental time were the same. This 
resulted in a similar final erosive profile in WISE 1 and WISE 2 from which the accretive wave conditions started.

$\Omega$ has traditionally been used to determine the overall beach tendency (erosion or accretion) for a given wave climate [25]. $\Omega$ was very similar in SANDS and in the WISE experiments under erosive conditions being slightly higher in SANDS. According to $\Omega$ values, the most accretive wave conditions were performed in WISE 2, followed by SANDS and being the least accretive in WISE 1. It can be noted that, consequently, in SANDS and WISE 2 the reduction of $\Omega$ from erosive to accretive wave conditions was larger than in WISE 1.

\begin{tabular}{cccccc}
\hline & Experiment & $H_{s}(\mathrm{~m})$ & $T_{p}(\mathrm{~s})$ & $\Omega(-)$ & $t(\mathrm{~min})$ \\
\hline \multirow{4}{*}{ Erosion } & SANDS & 0.53 & 4.14 & 3.77 & 1410 \\
& WISE 1 & 0.47 & 3.7 & 3.74 & 240 \\
& WISE 2 & 0.47 & 3.7 & 3.74 & 240 \\
\hline \multirow{4}{*}{ Accretion } & SANDS & 0.32 & 5.44 & 1.73 & 1225 \\
& WISE 1 & 0.32 & 4.7 & 2.00 & 930 \\
& WISE 2 & 0.27 & 5.3 & 1.50 & 960 \\
\hline
\end{tabular}

Table 1: Wave height $H_{s}(\mathrm{~m})$, wave period $T_{p}(\mathrm{~s})$, dimensionless sediment fall velocity $\Omega$ $(-)$ and duration $t$ (min) of erosive and accretive wave conditions in SANDS, WISE 1 and WISE 2.

\section{Data analysis}

\subsection{Water surface elevation}

Water surface elevation data were obtained at over 20 cross-shore locations in each experiment. This high number of measurements along the wave 
flume with a focus on data obtained in the highly dynamic surf and swash zones gives a reliable picture on the cross-shore development of the water surface elevation. The significant wave height $H_{s}$ is computed from the water surface elevation signal by means of spectral analysis as $H_{s}=4 \sqrt{m_{0}}$ where $m_{0}$ presents the zero order spectral moment.

The location where depth-induced wave breaking occurs (breakpoint) is determined as the location of the maximum relative wave height $\gamma=H_{s} / h$ where $h$ is the local water depth at the location of $H_{s}$. Parameters at the breakpoint will herinafter be indicated by the index $b$. Experimental and field measurements of $\gamma$ have shown maximum $\gamma$-values at the primary wave breaking location [26] although secondary maximum values close to the shoreline are also observed in unsaturated surf zones [26, 27]. Padilla and Alsina [28] have accurately measured individual wave breaking and correlated wave breaking with measured values of $\gamma$.

\subsection{Breaker bar characteristics}

The breaker bar characteristics, which are studied in this work, are primarily the cross-shore location $\left(x_{b a r}\right)$ and the height $\left(z_{b a r}\right)$ of the bar. A definition sketch illustrating the bar parameters is presented in figure 1 . The height of the bar is defined as the maximum elevation of the beach profile with respect to the initial, plane profile. In this work, we use the term 'bar height' for $z_{\text {bar }}$; in other studies $z_{\text {bar }}$ may be referred to as 'bar (crest) elevation' [e.g. 29]. The bar location $\left(x_{b a r}\right)$ is accordingly defined as the cross-shore location

of this maximum elevation. The water depth above $z_{b a r}$ with respect to the still water level is denoted as $h_{\text {bar }}$. 


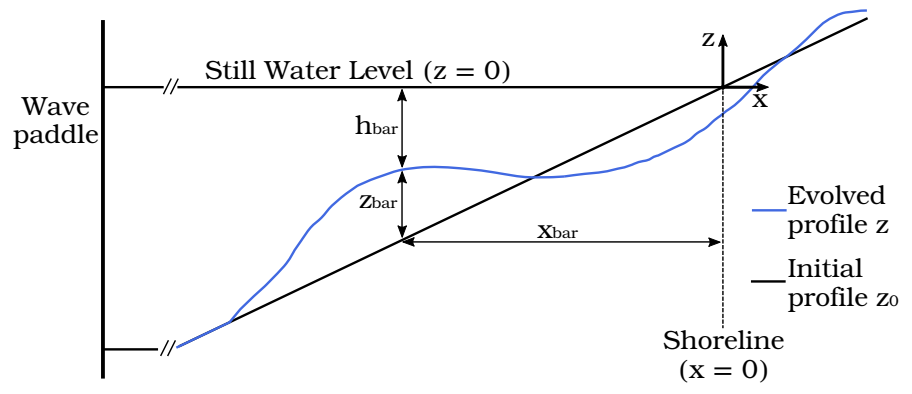

Figure 1: Definition of bar parameters.

\subsection{Sediment transport analysis}

Sediment transport rates $q\left(m^{3}\right) /(m \cdot s)$ at each cross-shore location $x_{i}(m)$ can be obtained from the change of the beach morphology $\Delta z$ during any time interval $\Delta t[23]$ :

$$
q\left(x_{i}\right)=q\left(x_{i-1}\right)-\int_{x_{i-1}}^{x_{i}}(1-p) \frac{\Delta z}{\Delta t} d x
$$

where $p(-)=0.4$ is the porosity of the sediment.

Positive (negative) values of $q$ indicate onshore (offshore) sediment transport.

An additional approach to study sediment transport is used in this work. Cross-shore velocity moments can be used a proxy for sediment transport as is was suggested by Russel and Huntley [30] and further extended by Mariño-Tapia et al. [12]. This concept is based on the energetics approach for sediment transport [31]. Mariño-Tapia et al. [12] found the processrelated ("third") velocity moments to be dominant in determining bedload sediment transport $[12,32]$. However, experimental measurements of mean suspended sediment concentration $\langle C(t)\rangle$ (where \langle\rangle denotes time averaging) 
have shown a good correlation with $\left\langle u^{2}(t)\right\rangle[21]$ and therefore, $\left\langle u^{3}(t)\right\rangle$ is also a good proxy of suspended sediment transport $\langle u(t) C(t)\rangle$.

In this work, this approach can be applied to the inner surf and swash zone in SANDS and to the surf and partially the shoaling zone in WISE IV due to the availability of velocity data. The raw cross-shore velocity signals were cleaned and filtered to eliminate spike noise and low quality data following e.g. Cáceres and Alsina [33], who applied the method of Goring and Nikora [34] to obtain the cross-shore velocity data $u(t)$.

\section{Results}

In this section, the results of the analysis of the three data sets (SANDS, WISE 1 and WISE 2) are presented. These results cover the beach profile evolution with a focus on the breaker bar dynamics, the sediment transport analysis and the paremeterisation obtained from beach profile data under erosive wave conditions. The results of the breaker bar dynamics are compared against numerous other large-scale beach profile data sets.

\subsection{Beach profile evolution}

The evolution of the beach profiles is shown in figure 2 for SANDS (top panels), WISE 1 (middle panels) and WISE 2 (bottom panels). Left panels illustrate the profile evolution under erosive wave conditions; right panels refer to accretive wave conditions. The initial 1/15 sloped profile (profile before erosive wave conditions were run) is shown as solid line. The final profiles obtained under the given wave conditions (dashed-dotted lines) as well as profiles after specific test times are presented. Accretive wave conditions started from the final profile obtained under erosive conditions. Therefore, 

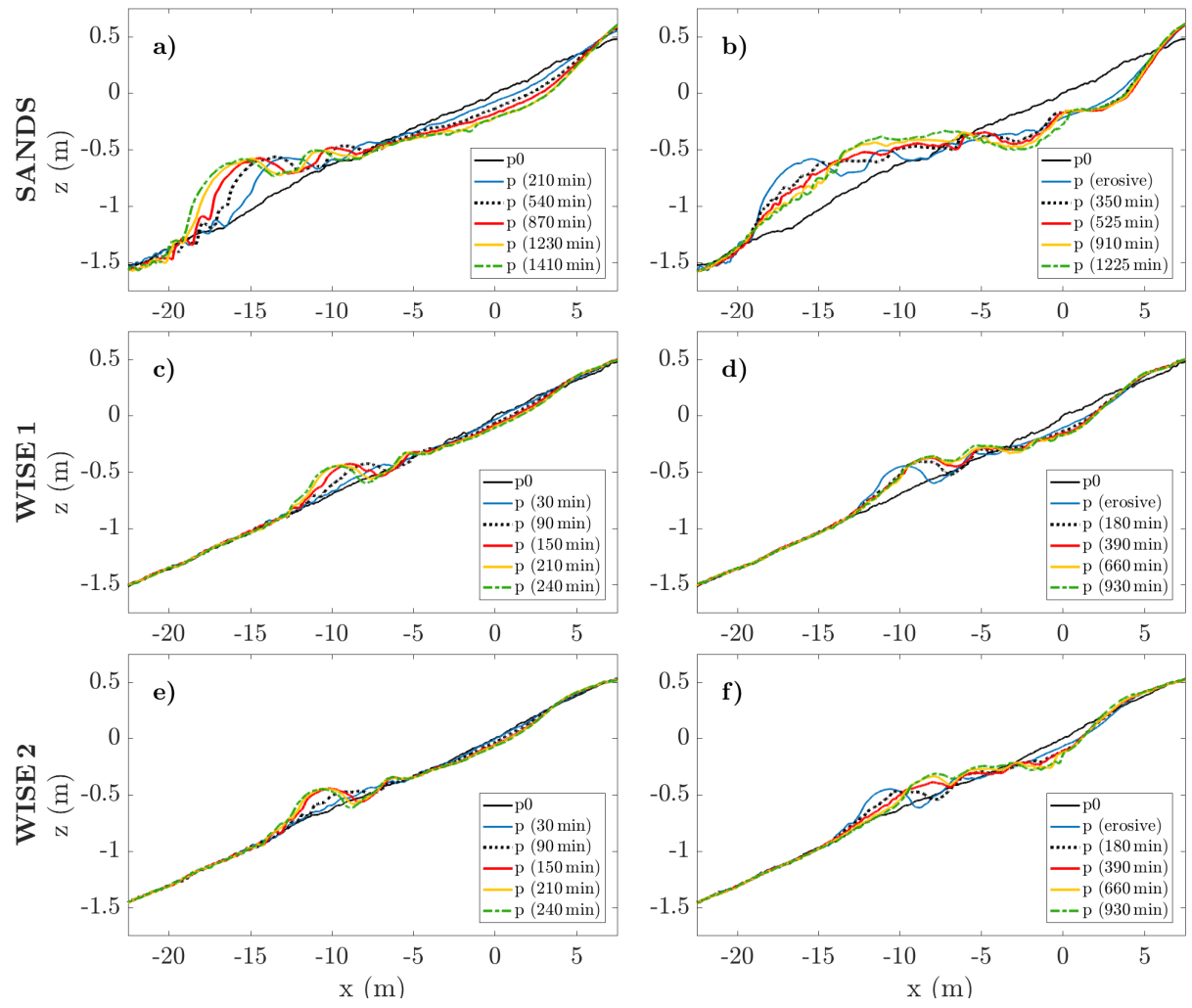

Figure 2: Evolution of beach profiles under erosive (left panels) and accretive (right panels) wave conditions in SANDS, WISE 1 and WISE 2 at selected time steps.

for accretive wave conditions (right panels of figure 2) this profile is also shown.

Under erosive wave conditions, a breaker bar evolves from the initial, 1/15 sloped beach profile and migrates offshore in all experiments (left panels in figure 2). A secondary bar (smaller in size) develops just onshore of the breaker bar and migrates offshore with it. At the end of the erosive wave conditions, the bar in SANDS is considerably larger in scale and it is found further offshore compared to WISE 1 and WISE 2. This observation is partly 
attributed to the longer duration of the erosive wave conditions in SANDS which lasted almost six times of the total duration of each WISE experiment. However, it can be noted that also after the same duration of erosive wave conditions (see profiles after $210 \mathrm{~min}$ ), the bar in SANDS is found further offshore $\left(x_{\text {bar }}=-13.4 \mathrm{~m}\right)$ and has a larger height $\left(z_{\text {bar }}=0.29 \mathrm{~m}\right)$ compared to WISE $1\left(x_{\text {bar }}=-10 \mathrm{~m}, z_{\text {bar }}=0.24 \mathrm{~m}\right)$ and WISE $2\left(x_{\text {bar }}=-10.8 \mathrm{~m}, z_{\text {bar }}=\right.$ $0.22 \mathrm{~m}$ ). $\Omega$ was only 0.03 larger in SANDS than in the WISE experiments which appears to be sufficient to result in a further offshore located, larger bar.

In addition, figure 2 reveals a very similar profile evolution in WISE 1 and WISE 2. This similar evolution was expected because the same erosive wave conditions were performed in both experiments. Average deviations between the bar height (location) are only about one centimeter (one meter) corresponding to ca. $15 \%$ (11\%) of the absolute height (cross-shore location) of the bar are assigned to hardly avoidable differences between the handmade initial beach profiles. Despite being very similar, at around the shoreline the initial profiles slightly deviate with a $0.9 \mathrm{~m}$ difference between the initial shoreline locations with respect to the wave paddle. These slight deviations are considered to be in the range of accuracy for large-scale morphodynamic experiments and therefore, the resulting final erosive beach profiles in WISE 1 and WISE 2, from which the accretive wave conditions started, are hereinafter considered to be the same.

After the change from erosive to accretive wave conditions, onshore bar migration occurs. A closer examination of the evolution of the breaker bar under accretive wave conditions reveals important differences between the 

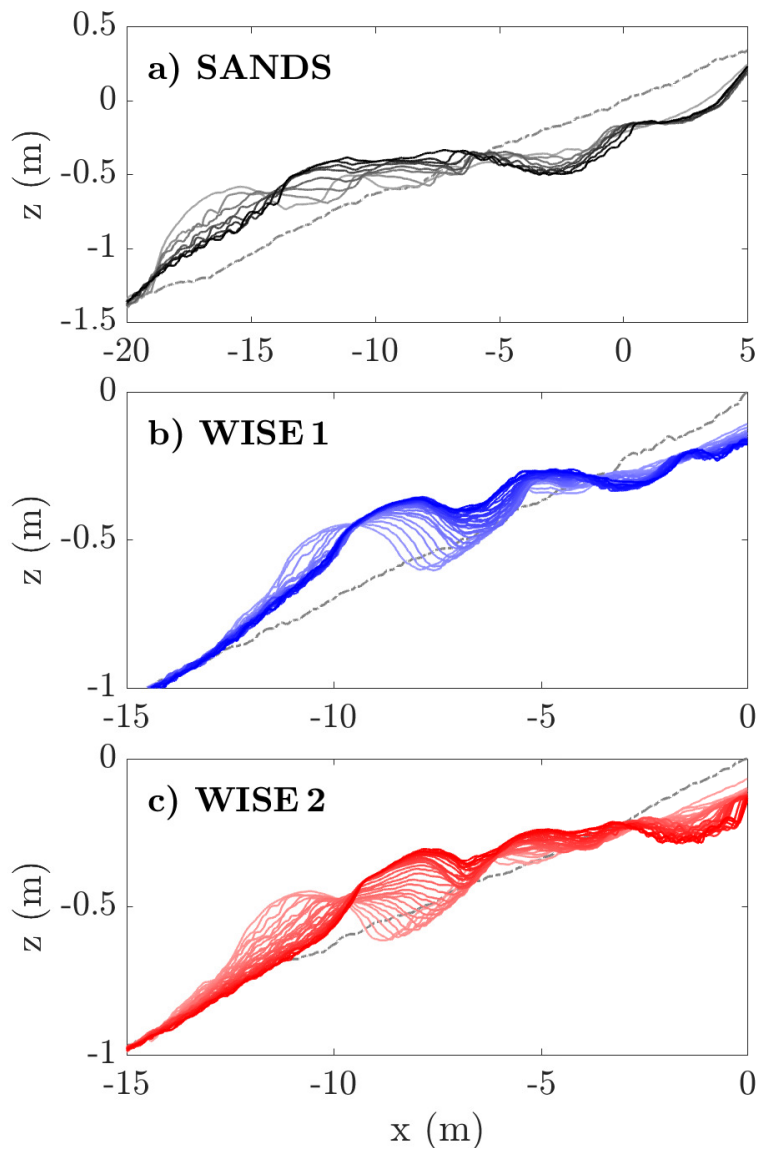

Figure 3: Breaker bar evolution under accretive wave conditions. All profiles obtained under accretive wave conditions are shown with colours changing from light to dark as time progresses. Measurement intervals were ca. $175 \mathrm{~min}$ in SANDS and ca. $30 \mathrm{~min}$ in WISE 1 and WISE 2. Dashed-dotted lines present the initial 1/15 sloped profile.

bar evolution in the three experiments. In order to obtain a better picture of the different patterns of breaker bar evolution, figure 3 shows all profiles obtained under accretive wave conditions. Starting from the last erosive beach profile (lightest colour), the colours become darker as the accretive test time progresses. Note the different scaling of the abscissa and ordinate 
in SANDS compared to WISE 1 and WISE 2.

In WISE 1 the bar keeps its shape during onshore migration. The onshore migration of the breaker bar occurs mainly at the very beginning of the accretive wave conditions. In contrast, the bar in WISE 2 changes its shape during onshore migration with an initial decay and subsequent recovery. These difference were similarly observed by Sánchez-Arcilla and Cáceres [22]. In the present work, these differences are studied in more detail and they are investigated for an additional set of data (SANDS). The secondary bar in both WISE 1 and WISE 2 remains at a relatively stable cross-shore location and merges with the breaker bar.

In all three experiments the depth of the trough (located inshore of ca. $x=-5 \mathrm{~m})$ continues to increase under accretive wave conditions. The trough deepening, which is traditionally associated with erosive wave conditions, indicate that beach erosion can continue even under accretive wave conditons as postulated by Baldock et al. [35].

In terms of the bar in SANDS, figure 3 suggests that the bar behaves similar to the bar in WISE 2: After an initial reduction in height, the bar migrates onshore and regrows (at least slightly) at the end of the performed accretive wave conditions. In SANDS, less profiles were obtained under accretive wave conditions than in the WISE experiments. However, the number of profiles is sufficient to observe the bar evolution clearly.

Based on the presented comparison, two patterns of breaker bar evolution under accretive wave conditions are distinguished for the present data: either a bar migrates entirely onshore with a slight height reduction (WISE 1) or a bar reduces its height more evidently, migrates onshore and possibly regrows 
(SANDS and WISE 2; where only in WISE 2 a bar height increase is very evident).

\subsection{Breaker bar dynamics}

In figure 4, the bar height is plotted against its corresponding crossshore location for each obtained beach profile. Left panels refer to profiles obtained under erosive wave conditions; right panels refer to profiles under accretive wave conditions. Diamonds mark the starting point of the graphs. In the top panels ( $\mathrm{a}$ and $\mathrm{b}$ ), absolute values of the bar heights and bar locations are shown. Because of the morphological differences between the experiments, it is useful to normalise the bar parameters and hence, make the bar evolution comparable. Bottom panels (c and d) show the bar height and the bar location normalised by their maximum values, which correspond to the values of the last profile obtained under erosive wave conditions. The small dots on the lines indicate the discrete values of $x_{b a r}$ and $z_{b a r}$. Note that the abscissa was set vice versa in panels a and d to make each graph readable from left to right.

For erosive wave conditions, the bars are formed at an onshore location (diamonds in a) and increase in height during offshore migration. Figure 4 reveals an overall linear relationship for both the absolute and the normalised bar parameters. It is noted that the individual data sets can partly deviate from this overall linearity (specifically WISE 2).

For the absolute bar parameters (figure 4a) the following function was fitted to the data $\left(R^{2}=0.85\right)$.

$$
z_{b a r}=-0.28-0.05 \cdot x_{b a r}
$$



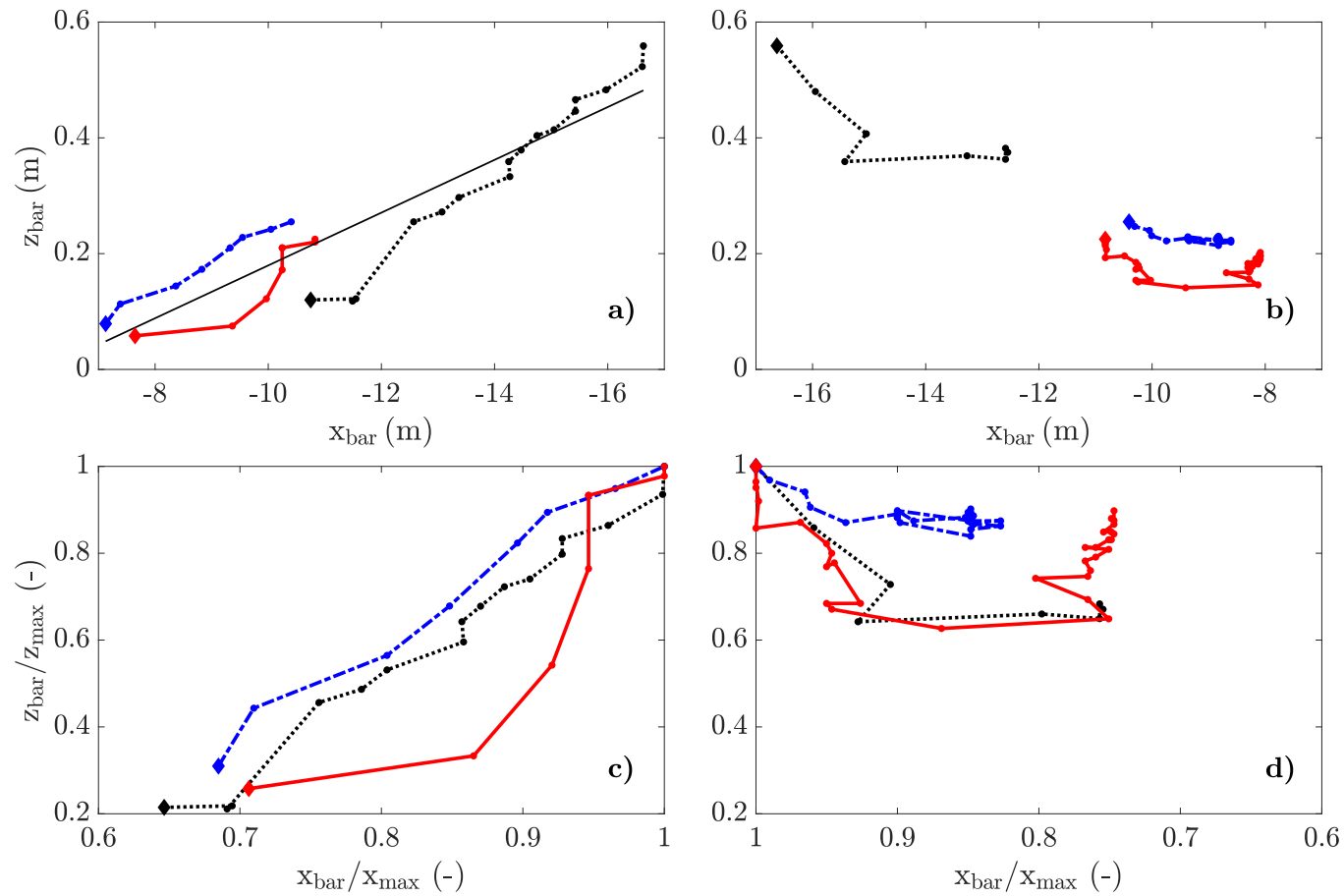

Figure 4: Top panels ( $\mathrm{a}$ and $\mathrm{b}$ ): Absolute bar height against absolute bar location under erosive (left panel) and accretive (right panel) wave conditions; bottom panels (c and d under erosive and accretive wave conditions, respectively): bar height and bar location normalised by maximum offshore location and height obtained during erosive wave conditions; diamonds mark the initial values; SANDS $(\cdot \cdots)$, WISE $1(\boldsymbol{-} \cdot \boldsymbol{-})$, WISE 2 $(-)$, linear fit $(-)$.

The coefficients in equation 2 may depend on beach slope and sediment characteristics.

It is acknowledged that, after a certain erosive test time, the bar would reach an equilibrium state without further growth and offshore migration. As can be noted from figure $2 \mathrm{a}, 2 \mathrm{c}$ and $2 \mathrm{e}$ the data show a fast bar migration during initial experimentation time and a progressivly slower bar migration with increasing experimentation time. This suggests a quasi-equilibrium situ- 
ation although an equilibrium point has not yet been reached. The reduction of the variability of the bar parameters with increasing experimentation time occurs for both the bar height and its cross-shore location and reaching a quasi-equilibrium situation does not affect the linear relationship between the two variables that is shown in figure 1a.

For accretive wave conditions, the figure confirms the previously observed two patterns of an either non-decaying or a decaying breaker bar. In WISE 1, the bar experiences only a very slight decrease in height and mainly migrates onshore in the beginning of the accretive wave conditions. The normalised figure (4d) shows that the bars from the independent experiments SANDS and WISE 2 behave in a similar way under accretive wave conditions: After an initial strong decrease in bar height, the bars migrate onshore at ca. $65 \%$ of their initial height. At ca. $75 \%$ of the initial location, the bar in WISE 2 regrows without further considerable onshore migration. The bar height increase in SANDS is very small and it cannot clearly be said if this small growth indicates the start of the recovery of the bar height. The duration of the accretive wave conditions in SANDS may have limited the entire evolution of the bar towards the end of the accretive tests. This is in accordance with Sánchez-Arcilla et al. [36] who reported for SANDS that the run times of the accretive tests limited full beach recovery. In addition to the accretive test time also the reduced water depth at the new bar location after onshore migration can limit bar growth. Due to these explained differences between the bar evolution in the experiments, in contrast to erosive wave conditions, an overall linear relationship between bar height and bar location is not evident for accretive wave conditions. 
Another parameter of interest for breaker bar evolution is the water depth above the bar $\left(h_{b a r}\right)$. It is obtained at the bar location so that the sum of $h_{b a r}$ and $z_{b a r}$ results in $z_{0}$ at the bar location (see also figure 1 ). Because $h_{b a r}$ is a location of low water depth, the relative wave height $\gamma=H_{s} / h$ often reaches its maximum for $h=h_{b a r}$ and hence, $h_{b a r}$ is important for breaker bar evolution. Similar to the normalisation of $z_{\text {bar }}$ in figure $4 \mathrm{c}$ and $4 \mathrm{~d}, h_{\text {bar }}$ of each obtained beach profile is normalised by $h_{b a r}$ at the end of the erosive wave conditions and plotted against the corresponding normalised bar location.
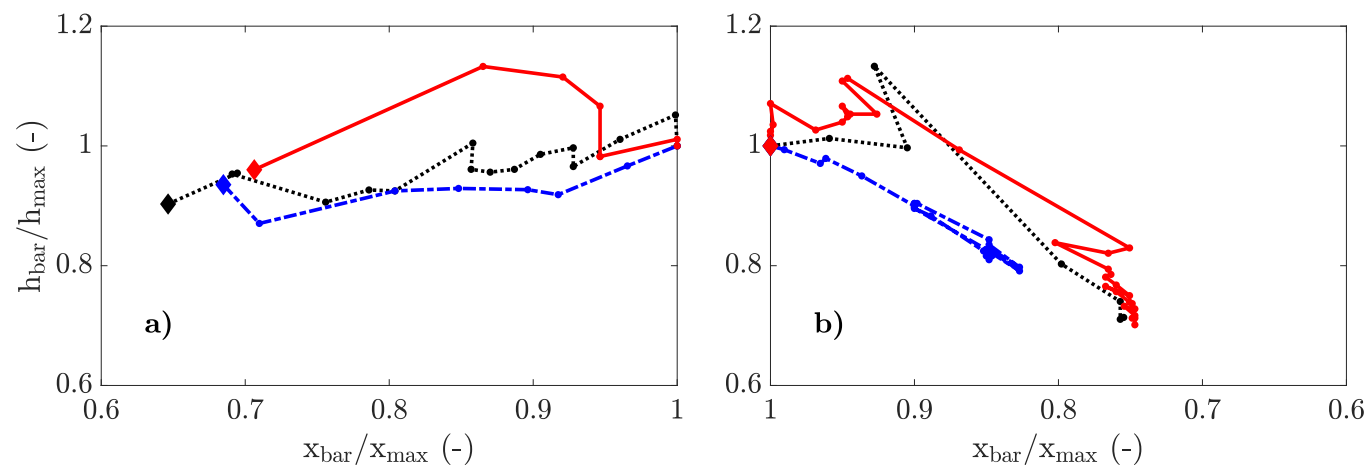

Figure 5: Water depth above bar $h_{b a r}$ normalised by $h_{b a r}$ at the end of erosive wave conditions for a) erosive and b) accretive wave conditions; diamonds mark the initial values; SANDS $(\cdots)$, WISE $1(\boldsymbol{\cdots} \cdot \boldsymbol{-})$, WISE $2(\square)$.

Under erosive wave conditions (figure 5a), a slight increase of $h_{b a r}$ occurs in SANDS and WISE 1; in WISE 2 this trend is not as evident, similar as for the change of bar height against the bar location (figure 4c). Figure 5a indicates that despite the increase in bar height (figure 4c) the water depth increases as the bar migrates offshore over the sloping bed. Hence, after longer durations of erosive wave conditions, $h_{b a r}$ would keep increasing until it becomes too large to affect wave breaking and waves would start breaking 
further onshore as reported in previous studies [e.g. 37, 38].

Under accretive wave conditions (figure 5b) the change of $h_{b a r}$ reflects the changes in bar height during onshore migration as shown in figure $4 \mathrm{~d}$. In WISE $1 h_{\text {bar }}$ decreases linearly highlighting that the bar experiences only a slight decrease in bar height as it migrates onshore over the sloping bed. In SANDS and WISE 2 an initial increase of $h_{\text {bar }}$ is noted reflecting the bar decay. The maximum $h_{\text {bar }}$ matches the minimum $z_{\text {bar }}$ in SANDS; in WISE 2 it happens one profile measurement $(30 \mathrm{~min})$ before the minimum $z_{b a r}$ is reached. Subsequently, $h_{b a r}$ decreases during onshore migration as can be expected from the constant height at which the bar migrates onshore. In WISE 2 a final strong decrease in $h_{\text {bar }}$ occurs representing the bar height increase at a constant cross-shore location.

\subsection{Sediment transport}

Sediment transport rates computed using equation 1 are plotted against the cross-shore location for comparable time intervals of erosive and accretive wave conditions in figure 6 . The cross-shore location was normalised by the bar location to illustrate sediment transport rates with respect to the bar

location. Hence, the bar is located at $x / x_{\text {bar }}=1$ and $x / x_{b a r}>1\left(x / x_{b a r}<1\right)$ is offshore (onshore) of the bar. Note that because this normalisation reverses the sign of on-/offshore direction, the abscissa is set vice versa in all figures where the normalised bar location is used. This makes the offshore (onshore) direction appear on the left (right) as in the plots of the beach profiles. Note the different scales on the ordinates of figure $6 \mathrm{a}$ and $\mathrm{b}$.

Figure 6a shows strong offshore sediment transport between the shoreline and the bar where it is strongest for SANDS. Also pronounced onshore sed- 
iment transport offshore of the bar can be noted in SANDS. This sediment transport pattern results in the formation of an offshore migrating bar in all three experiments. In WISE 1 offshore sediment transport rates are slightly larger than in WISE 2 even though the same wave conditions were performed. This might also give an indication for the slight profile differences between WISE 1 and WISE 2 in addition to the abovementioned small differences in initial seabed conditions.

Figure $6 \mathrm{~b}$ reveals a qualitatively similar sediment transport pattern between the experiments with onshore sediment transport slightly offshore of the bar location and offshore sediment transport betweeen the bar and the shoreline. However, magnitudes of the sediment transport rates are different. In case of the non-decaying bar (WISE 1) onshore sediment transport at the bar is relatively weak and offshore transport is relatively strong. The opposite is the case in WISE 2 (decaying bar). In SANDS both on- and offshore sediment transport are relatively strong even though wave conditions were not the least accretive of the three experiments.

To study the differences in sediment transport rates in more detail, figure 7 shows sediment transport rates during similar time intervals before (solid lines) and after bar decay (dashed lines) in SANDS (figure 7a) and WISE 2 (figure 7c). A similar pattern can be noted: During bar decay onshore transport at the bar crest is strong in both SANDS and WISE 2 and additionally, offshore transport is very weak in WISE 2. This results in bar decay as sediment from the bar crest is moved onshore. After the bar has decayed, onshore sediment transport at the bar reduces and offshore transport onshore of the bar increases (remains at a similar rate) in WISE 2 (SANDS). This change 

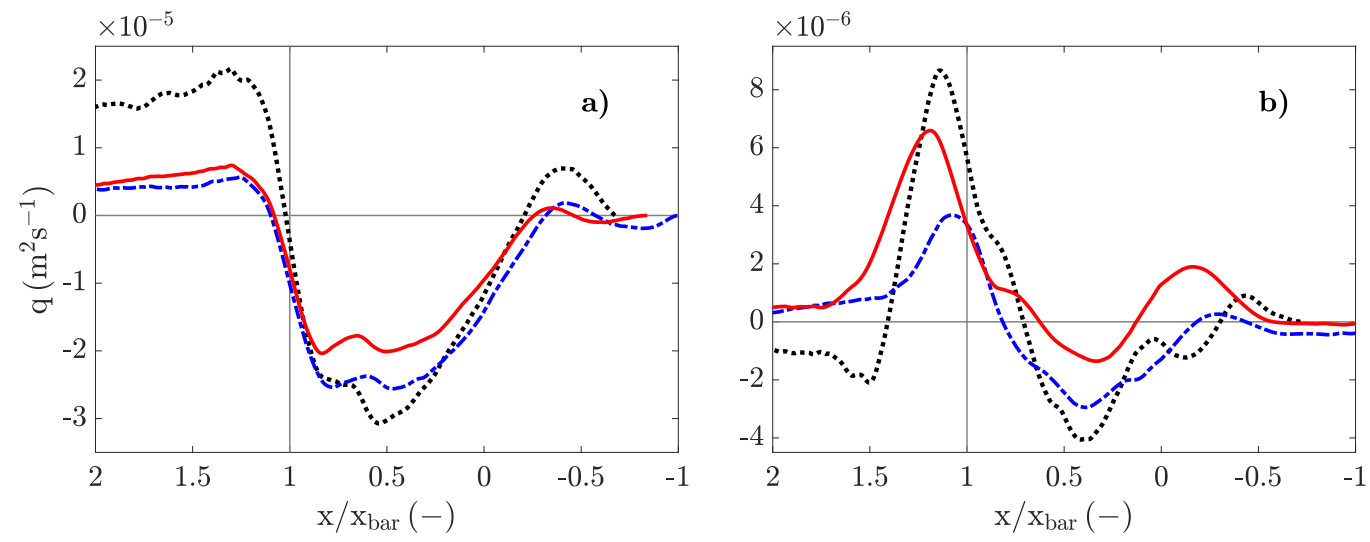

Figure 6: Sediment transport rates under a) erosive (after $210 \mathrm{~min}$ ) and b) accretive wave conditions (after $910 \mathrm{~min}$ in SANDS and $900 \mathrm{~min}$ in WISE IV) against normalised crossshore location; SANDS $(\cdot \cdots)$, WISE $1(\boldsymbol{-} \cdot \boldsymbol{-})$, WISE $2(-)$; onshore direction is towards the right.

in sediment transport rates allows potential re-evolution of the bar.

In WISE 1 (almost non-decaying bar) (figure 7b) the same time intervals as in WISE 2 were chosen for temporal comparability. Onshore transport at the bar is weaker than in WISE 2 and offshore transport is stronger preventing bar decay during onshore migration. This suggests that the less accretive wave conditions in WISE 1 result in more intense wave breaking, stronger undertow and stronger offshore sediment transport just onshore of the bar compared to WISE 2. This stronger offshore sediment transport in WISE 1 enhances the convergence of onshore and offshore sediment transport onshore of the bar location and prevents the bar from decaying. After $360 \mathrm{~min}$ the bar has reached a relatively stable location and height (see figure 2d) and onshore transport at the bar as well as offshore transport onshore of the bar show reduced magnitudes. 

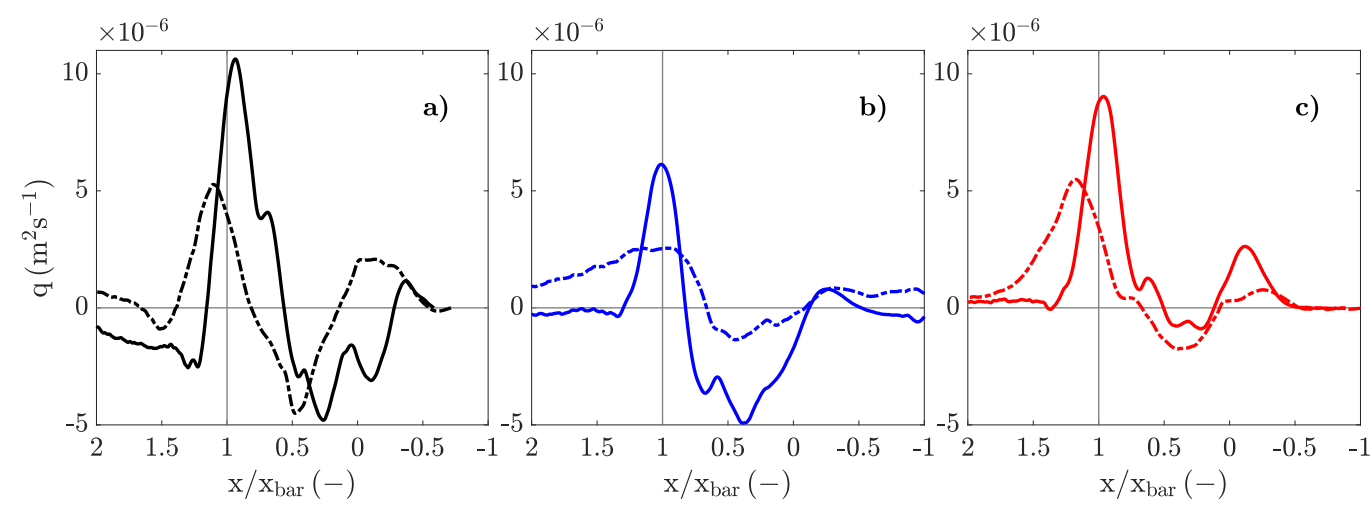

Figure 7: Sediment transport rates under accretive wave conditions in a) SANDS (0$525 \mathrm{~min} \longrightarrow$ and $525-1085 \mathrm{~min}-\cdot-$ ), b) WISE 1 (0-360 $\mathrm{min} \longrightarrow$ and $360-720 \mathrm{~min}$ - - - ) and c) WISE $2(0-360 \mathrm{~min} \longrightarrow$ and $360-720 \mathrm{~min}-\cdot-)$; normalised cross-shore location on the abscissa; onshore direction is towards the right.

As explained in section 3, normalised velocity moments can be used as a proxy for sediment transport magnitudes. Figure 8 shows the normalised third cross-shore velocity moments against the normalised cross-shore location for erosive (8a) and accretive (8b) wave conditions. Following the approach of Mariño-Tapia et al. [12], positive (negative) values of the velocity moments indicate onshore (offshore) sediment transport.

The distribution of the normalised velocity moments indicates similar sediment transport patterns as the ones shown in figure 6 . This means that there are similar offshore sediment transport distributions between the experiments in the region between the bar and the shoreline under erosive conditions and more variable sediment transport distributions under accretive conditions. The larger offshore sediment transport magnitude in WISE 1 just onshore of the bar compared to WISE 2 and the onshore transport around the bar in WISE 2 support the differences in sediment transport obtained from the 

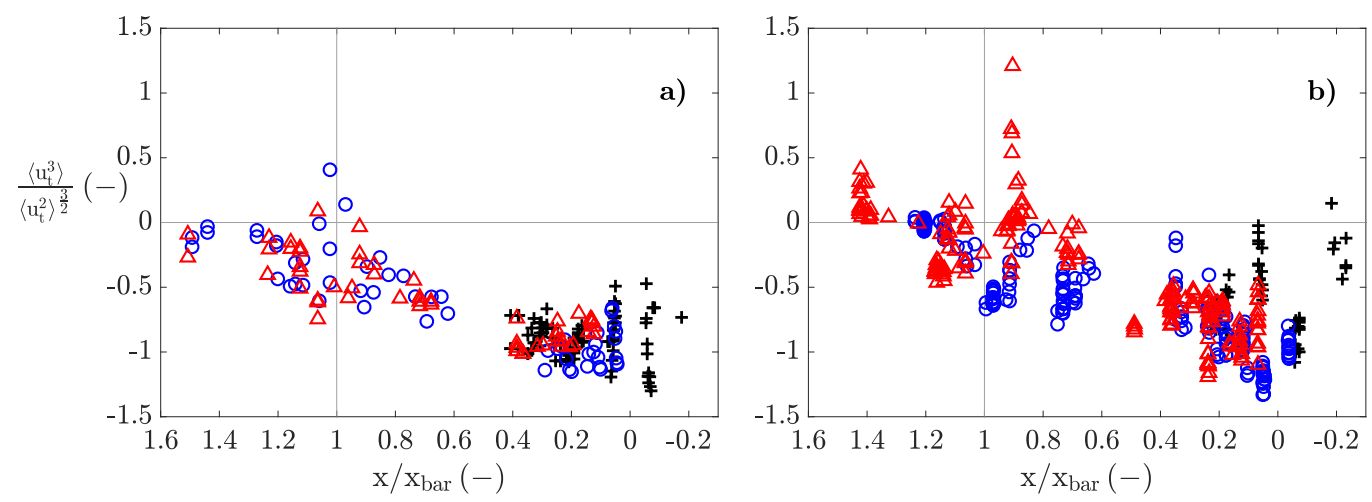

Figure 8: Normalised third velocity moments under a) erosive and b) accretive wave conditions against cross-shore location normalised by bar location; SANDS $(+)$, WISE 1 $(\bigcirc)$, WISE $2(\triangle)$; onshore direction is towards the right.

morphology for accretive conditions (see figure 6b).

\subsection{A simple model for beach profile evolution under erosive wave conditions}

This section presents an approach to model beach profile evolution under erosive wave conditions. For each beach profile $(z)$ obtained under erosive wave conditions the elevation with respect to the initial profile $\left(z_{0}\right)$ was computed as a relative beach profile $\Delta z=z-z_{0}$. Each relative beach profile was normalised by its bar height $z_{b a r}$ (maximum of its corresponding $\Delta z$ ); the cross-shore coordinates were normalised by the corresponding bar location $x_{b a r} . z_{b a r}$ and $x_{b a r}$ account for the same time interval of erosive wave conditions as $\Delta z$.

As illustrated in figure 9, all normalised beach profiles follow a very similar shape under erosive wave conditions. Note that the abscissa is reversed to make the onshore direction appear on the right as in the other figures. The similar shape of the beach profiles is linked to the very similar sediment 
transport magnitudes under erosive wave conditions as indicated by sediment transport rates obtained from both the morphology (figure 6a) and velocity moments (figure 8a). Figure 9 only shows the profiles in the active part of the beach where the bar evolves and where important bed evolution occurs. Because each $\Delta z$ and the bar quantities used for normalisation correspond to the same time interval, the normalised bar height is always at $z / z_{\text {bar }}=1$ and the normalised bar location at $x / x_{b a r}=1$.

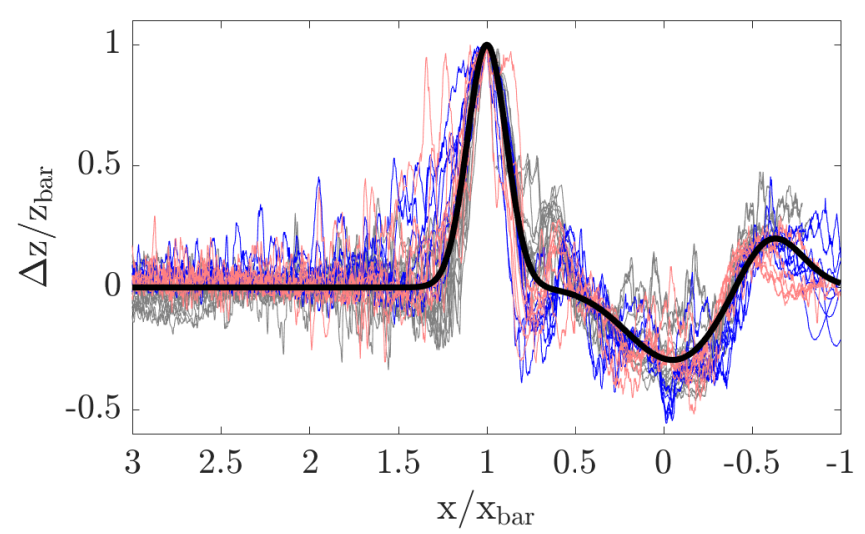

Figure 9: Relative beach profiles under erosive wave conditions normalised by bar parameters and fitted function; SANDS ( - ), WISE $1(-)$, WISE $2(-)$, fitted function $\left(R^{2}=0.85\right)(-)$; onshore direction is towards the right.

The following combination of three Gaussian functions (bold line in figure $\left.9 ; R^{2}=0.67\right)$ is fitted to the data:

$$
\Delta z_{n}=0.23 \cdot e^{-\left(\frac{x_{n}+0.60}{0.25}\right)^{2}}-0.30 \cdot e^{-\left(\frac{x_{n}+0.06}{0.38}\right)^{2}}+1.00 \cdot e^{-\left(\frac{x_{n}-1.00}{0.16}\right)^{2}}
$$

where $x_{n}=x / x_{b a r}$ and $\Delta z_{n}=\Delta z / z_{b a r}$. 
This parameterisation is based on a data fitting of beach profile data obtained under erosive wave conditions. For profiles under accretive wave conditions, a similar parameterisation cannot be obtained. This is because the initial profile of the accretive conditions was the barred profile after erosive wave conditions (not $z_{0}$ ) whereas the normalisation parameters $x_{\text {bar }}$ and $z_{\text {bar }}$ are defined with respect to the plane profile $\left(z_{0}\right)$. Therefore, a normalisation as for profiles under erosive wave conditions cannot be performed. Referring the profiles under accretive wave conditions to the plane 1/15 sloped profile, in contrast, would include beach profile changes from previous erosive wave conditions instead of separately studying profiles under accretive wave conditions.

The relationship in equation 3 can be used to reproduce beach profiles under erosive wave conditions for SANDS and WISE IV based on the wave breaking location as only hydrodynamic input parameter. The breaking location $x_{b}$ is linked to the bar location $x_{b a r}$ as shown in figure 10 for erosive (a) and accretive (b) wave conditions with the linear relationship $\left(R^{2}=0.89\right)$ for erosive wave conditions described by equation 4 .

$$
x_{\text {bar }}=1.69+1.1 \cdot x_{b}
$$

To obtain a predicted beach profile $z_{p}$ the following major steps are required:

1. obtain $x_{b a r}$ of a desired profile from $x_{b}$ using equation 4 ;

2. obtain $x_{n}=x / x_{\text {bar }}$ as input for equation 3 ;

3. compute $\Delta z_{n}$ using equation 3 ;

4. compute $z_{b a r}$ using the relationship between $x_{b a r}$ and $z_{b a r}$ (equation 2); 

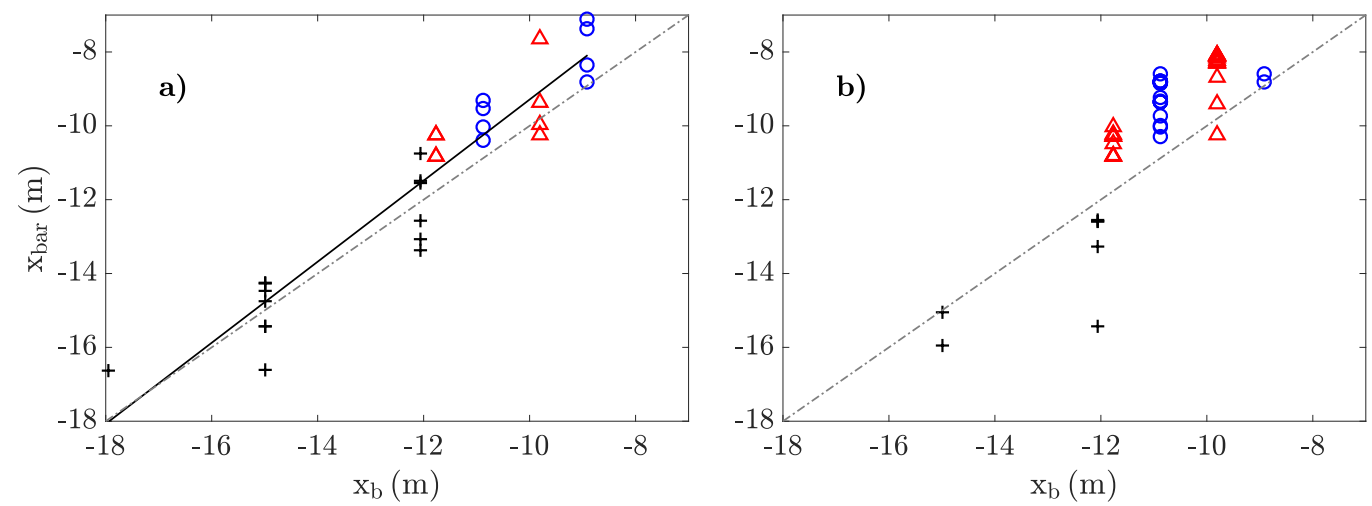

Figure 10: Bar location $x_{\text {bar }}$ against location of wave breaking $x_{b}$ under a) erosive and $\mathrm{b}$ ) accretive wave conditions; SANDS $(+)$, WISE $1(\bigcirc)$, WISE $2(\triangle)$, linear fit $\left(R^{2}=0.89\right)$ $(-)$, identity line $(-\cdot-)$.

5. obtain the predicted beach profile $z_{p}=\left(\Delta z_{n} \cdot z_{b a r}\right)+z_{0}$ using the initial $1 / 15$ sloped beach profile $z_{0}$ of the experiments.

Figure 11 shows measured (dotted lines) and predicted (solid lines) beach profiles of SANDS (top panels), WISE 1 (middle panels) and WISE 2 (bottom panels). Because the total erosive test time was different in the three experiments, profiles are shown at the same fraction of the total erosive test time (at $38 \%, 62 \%$ and $100 \%$ of the total erosive test time in the left, middle and right panels, respectively).

A common parameter to quantify the performance of morphological models is the Brier Skill Score (BSS) [39]:

$$
B S S=1-\left[\frac{\left\langle\left(\left|z_{p}-z_{m}\right|-\Delta z_{m}\right)^{2}\right\rangle}{\left\langle\left(z_{0}-z_{m}\right)^{2}\right\rangle}\right]
$$

where $z_{p}$ is the predicted profile, $z_{m}$ the measured profile and $z_{0}$ the initial profile. $\Delta z_{m}$ is the allowed error of the measured bed level and corresponds 
to the accuracy of the profiler $\left(\Delta z_{m}=10 \mathrm{~mm}\right.$ in the CIEM). Angle brackets $(\langle\ldots\rangle)$ indicate time averaging. The quantification of model performance by van Rijn et al. [39, table 2] is used in this work.
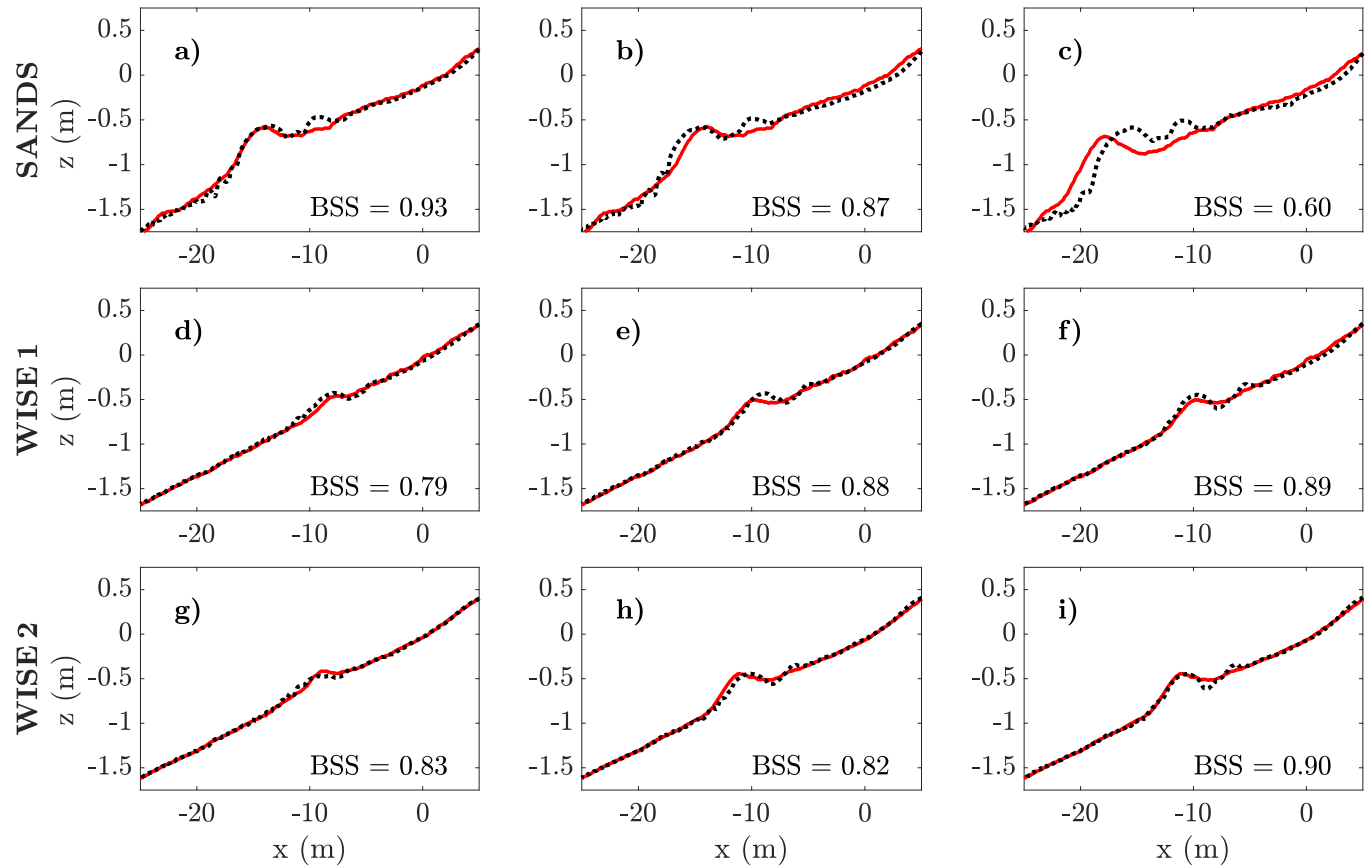

Figure 11: Measured (...) and predicted ( - ) profiles after $38 \%(\mathrm{a}, \mathrm{d}, \mathrm{g}), 62 \%(\mathrm{~b}$, $\mathrm{e}, \mathrm{h})$ and $100 \%(\mathrm{c}, \mathrm{f}, \mathrm{i})$ of the erosive test time.

Figure 11 shows that the model is well capable of reproducing the measured beach profiles. The BSS is usually above 0.8 indicating excellent model performance; only figure 11c (final profile under erosive wave conditions in SANDS) shows a lower BSS value. It needs to be noted that the cross-shore resolution of water surface elevation measurements was importantly lower (usually between one and two orders of magnitude lower) than the resolution of the beach profile measurements. These differences in measurement resolution influence the accuracy of the reproduced beach profile and show the 
high dependency on the accurate determination of the wave breaking location for good model performance. In addition, the model does not account for multiple bars on a beach profile as it can be noted mainly for SANDS where a small secondary bar has evolved just onshore of the breaker bar.

The presented model will need to be tested with other data sets to investigate its validity and its limitations. In its present form, the model is most likely only capable of reproducing beach profiles obtained in the CIEM with the same sediment characteristics and a similar beach slope because the defined relationship between bar height and bar location is based on absolute values which vary for different experiments (as shown in figure 12a).

The most promising aspect of the presented model is clearly its simplicity. Based on only the wave breaking location and knowledge about the initial beach profile, it is capable of reproducing the beach profiles studied in this work.

It is important to note that the presented model only holds for profile evolution under erosive wave conditions. Even though a linear relationship between the breaking location and the bar location, similar to equation 4 , could be defined for accretive wave conditions, determination of bar height from bar location is not straightforward because the bars follow different evolution patterns.

\subsection{Comparison with other large-scale beach profile data}

The relationship between the height and the cross-shore location of the breaker bar under erosive and accretive wave conditions has been presented for the three data sets obtained in the CIEM (figure 4). In order to investigate to what extent the presented bar dynamics hold in a more general way, 
they are contrasted with numerous other available large-scale experimental data of beach profiles. It is important to note that the availability of comparable data sets is very limited, especially beach profile data under accretive wave conditions. The following additional beach profile data were used for comparison:

- LIP 11 Data, obtained in the Delta Flume in 1993 [40]

- SANDS Data GWK, obtained in Grosser Wellen Kanal (GWK), Hannover, in 2007 [41]

- SAFE Data GWK, obtained in Grosser Wellen Kanal (GWK), Hannover, in 1996/97 [42]

- CRIEPI Data, obtained in the Large Wave Flume (LWF) of the Central Research Insitute of Electric Power Industry, Japan, in 1996 [43]

- CROSSTEX Data, obtained in the Large Wave Tank (LWT) at Oregon State University's O H Hinsdale Wave Research Laboratory in 2005 [44]

- SUPERTANK (ST) Data, obtained in the Large Wave Tank (LWT) at Oregon State University's O H Hinsdale Wave Research Laboratory in $1991[45]$

Wave flume dimensions, representative sediment size, slope of the active beach profile and wave conditions of all studied data sets are summarised in table 2 (including SANDS, WISE 1 and WISE 2 for completeness). $\Omega$ is not indicated in table 2 because measured sediment settling velocities $w_{s}$ were not available for all data. Computed values of $w_{s}$, which were obtained based 
on the sediment force balance, differed $15-30 \%$ from measured $w_{s}$ values with a consequently important influence on $\Omega$. This makes a comparison between $\Omega$ values based on measured $w_{s}$ and $\Omega$ values based on computed $w_{s}$ difficult.

Erosive wave conditions started from an initial beach profile which was usually a plane profile, except for CROSSTEX where the profile was not completely plane (see [44], figure 1). The accretive beach profile data had to start from a barred beach profile to study breaker bar response to the change of wave conditions. This further limited the available data sets for accretive wave conditions. In the LIP 11 experiment, initially, slightly erosive conditions were performed which were followed by stronger erosive wave conditions (values in parentheses) before accretive wave conditions started. The barred initial profile of the accretive wave conditions of the SUPERTANK experiment (ST 30) was created by previous runs of random waves and was not the final profile of the erosive wave conditions (ST 10). Both ST 10 and ST 30 consisted of more tests and profile measurements but under changed wave conditions. Therefore, only the first profiles which were obtained under the same wave conditions are used here.

Figure 12 extends the plot of the (normalised) bar parameters of SANDS, WISE 1 and WISE 2 (figure 4) using the additional beach profile data. Note the different axes scaling compared to figure 4 as well as within figure 12 between the subplots of erosive and accretive wave conditions.

For erosive wave conditions, the figure reveals an overall linear relationship between the bar parameters for all experiments with only slight differences of the gradients. This becomes particularly evident from the nor- 


\begin{tabular}{|c|c|c|c|c|c|c|c|c|c|c|c|c|}
\hline \multicolumn{2}{|c|}{ Experiment } & \multicolumn{3}{|c|}{ Flume dimensions $(m)$} & \multirow{2}{*}{ 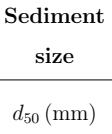 } & \multirow{2}{*}{$\begin{array}{l}\text { Mean active } \\
\text { beach slope } \\
m(-)\end{array}$} & \multicolumn{3}{|c|}{ Erosive conditions } & \multicolumn{3}{|c|}{ Accretive conditions } \\
\hline & & Length & Width & Height & & & $H_{s}(\mathrm{~m})$ & $T_{p}(\mathrm{~s})$ & $t(\min )$ & $H_{s}(\mathrm{~m})$ & $T_{p}(\mathrm{~s})$ & $t(\min )$ \\
\hline \multirow{3}{*}{ CIEM } & SANDS & \multirow{3}{*}{100} & \multirow{3}{*}{3} & \multirow{3}{*}{4.5} & \multirow{3}{*}{0.25} & $1 / 15$ & 0.53 & 4.14 & 1410 & 0.32 & 5.44 & 1225 \\
\hline & WISE 1 & & & & & $1 / 15$ & 0.47 & 3.7 & 240 & 0.32 & 4.7 & 930 \\
\hline & WISE 2 & & & & & $1 / 15$ & 0.47 & 3.7 & 240 & 0.27 & 5.3 & 960 \\
\hline Delft & LIP 11 & 233 & 5 & 7 & 0.22 & $1 / 55$ & $0.9(1.4)$ & $5(5)$ & $720(1080)$ & 0.6 & 8 & 780 \\
\hline \multirow{2}{*}{ GWK } & SANDS & \multirow{2}{*}{324} & \multirow{2}{*}{7} & \multirow{2}{*}{5} & 0.28 & $1 / 15$ & 1 & 5.6 & 1970 & 0.6 & 7.71 & 1890 \\
\hline & SAFE A9 & & & & 0.3 & $1 / 40$ & 1.2 & 5.5 & 1510 & - & - & - \\
\hline \multirow{3}{*}{ CRIEPI } & L3 & \multirow{3}{*}{205} & \multirow{3}{*}{3.4} & \multirow{3}{*}{6} & \multirow{3}{*}{0.97} & $1 / 20$ & 1 & 5 & 960 & - & - & - \\
\hline & L5 & & & & & $1 / 10$ & 1.2 & 3 & 480 & - & - & - \\
\hline & L6 & & & & & $1 / 10$ & 1 & 3 & 960 & - & - & - \\
\hline \multirow{3}{*}{ LWT } & CROSSTEX & \multirow{3}{*}{104} & \multirow{3}{*}{3.7} & \multirow{3}{*}{4.6} & \multirow{3}{*}{0.22} & $1 / 20$ & 0.6 & 4 & 180 & 0.4 & 7 & 300 \\
\hline & ST 10 & & & & & $1 / 13$ & 0.8 & 3 & 270 & - & - & - \\
\hline & ST 30 & & & & & $1 / 13$ & - & - & - & 0.4 & 8 & 200 \\
\hline
\end{tabular}

Table 2: Studied large-scale experimental data.

malised bar parameters (figure 12c). Considering that the experiments (except SANDS and SANDS GWK as well as WISE 1 and WISE 2) were setup entirely independently from each other and that the bar is described by only two discrete values, the agreement of the normalised bar parameters from the different experiments is remarkable. Differences are mainly associated with differences in sediment characteristics and beach slopes.

In terms of accretive wave conditions, figure 12 (b and d) underlines the previous finding that the relationship between the bar parameters does not follow a single, relatively simple pattern as under erosive wave conditions. The distinction between decaying and non-decaying bars during onshore migration cannot be perfectly confirmed. However, a closer examination reveals certain trends of the bar dynamics. SANDS GWK shows an initial bar 
height reduction followed by onshore bar migration, similar to SANDS and WISE 2, even though the normalised bar height reduction is weaker. Bar height increase following decay and onshore migration is only clearly pronounced in WISE 2. In SANDS GWK a height increase of the bar is weakly indicated but not very evident, similar to SANDS. This is not surprising because SANDS GWK was carried out as prototype experiment within the SANDS project with similar beach profile evolution of SANDS in GWK and CIEM [36].

The bar in the CROSSTEX experiment shows, just as during erosive wave conditions, relatively little migration. The normalised figure (figure 12d) reveals that the bar behaves similar to a non-decaying bar (disregarding the values that peak towards onshore movement and bar growth in the beginning of accretive wave conditions).

LIP 11 and ST 30 do not match either of the trends of bar response under accretive wave conditions. In LIP 11, the bar migrates initially offshore before it migrates onshore and continues to grow. The bar in LIP 11 under accretive wave conditions was already described by Sánchez-Arcilla et al. [40] as migrating in an unexpected direction. The bar in ST 30 reduces its height but migrates offshore. In terms of ST 30 it should be noted that the initial bar had a pronounced peak and was forward leaning. During the six profiles obtained under the short accretive test time, the bar was slightly smoothened but the time was not sufficient to result in a considerable bar response. 

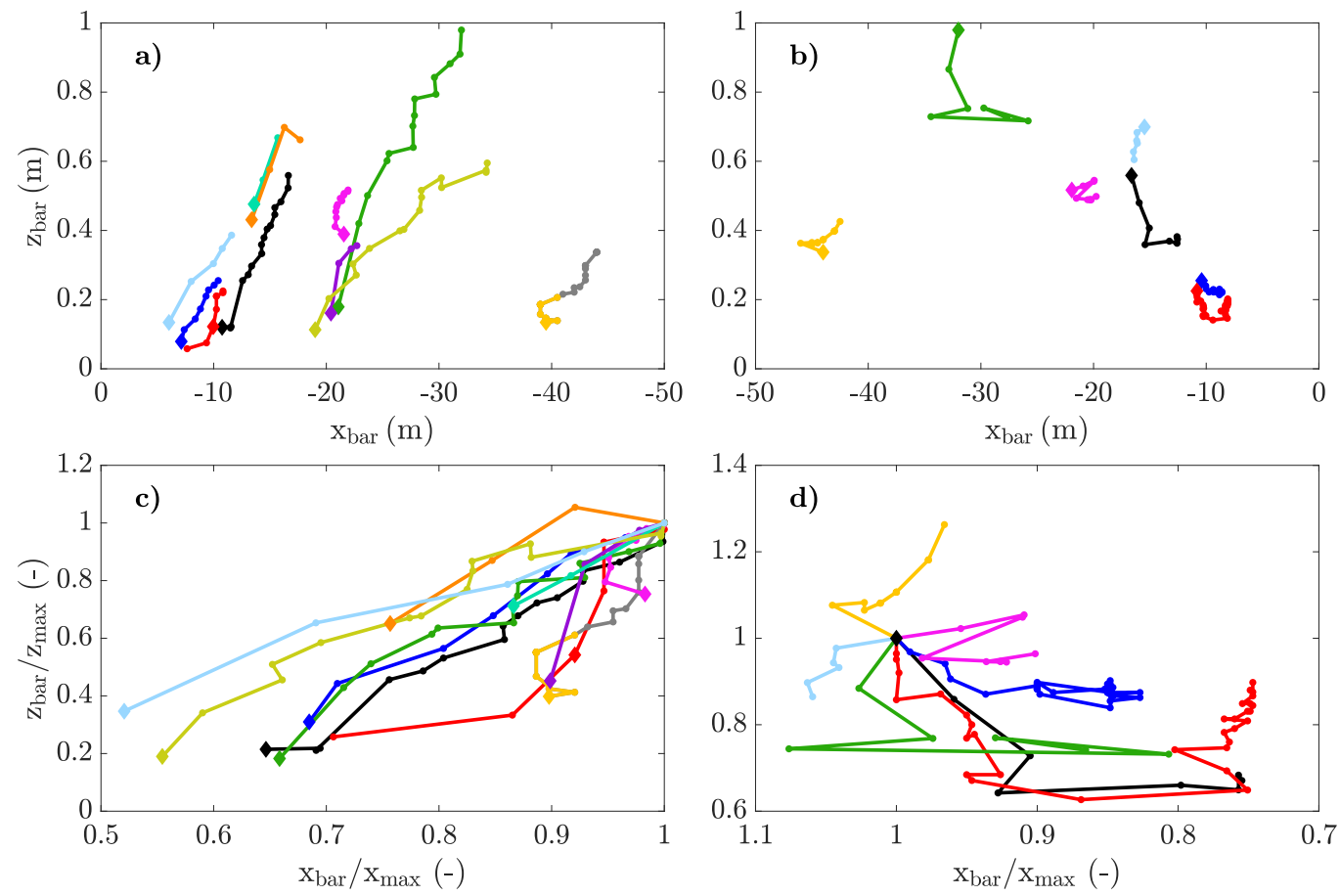

Figure 12: Bar height against bar location under erosive (left panels) and under accretive (right panels) wave conditions for all data sets; absolute values in upper panels; normalised values in bottom panels; diamonds mark the initial values; SANDS ( - ), WISE 1

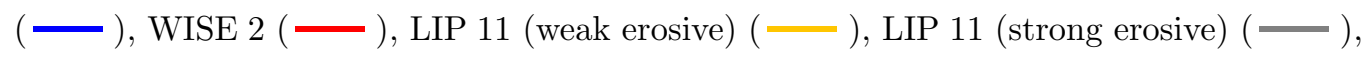
SANDS GWK ( - ), GWK SAFE A9 ( - $)$, CRIEPI L3 ( - ), CRIEPI L5 ( - ), CRIEPI L6 ( -$)$, CROSSTEX ( - ), SUPERTANK ( - ).

\section{Discussion}

From the results presented in this work it can clearly be noted that breaker bars show different behaviour under erosive and accretive wave conditions. This section discusses the differences in breaker bar evolution and refers primarily to the three data sets obtained in the CIEM (SANDS, WISE 1 and WISE 2). 


\subsection{Erosive wave conditions}

The results in this work provide evidence of a very similar evolution of breaker bars under erosive wave conditions. This similar evolution is mainly captured by the linear relationship between the bar height and the bar location which is well supported by numerous large-scale experimental data sets (figure 12). An increasing height of offshore migrating bars was already

reported by prior studies, such as Ruessink and Terwindt [46], but without a closer examination of the relationship between the bar height and the bar location.

The linear relationship between the bar parameters suggests that the evolution of breaker bars under high energy wave conditions is dominated by the energetic conditions of the incident waves and the resulting wave breaking location. More specifically, under high energy wave conditions large waves break either at the bar crest or offshore of it where the relative wave height $(H / h)$ becomes too large. In the cross-shore region onshore of the breakpoint, the offshore-directed undertow moves sediment offshore and is mainly responsible for breaker bar formation and its offshore migration. For SANDS, WISE 1 and WISE 2, the dominant influence of the wave conditions is supported by similar cross-shore sediment transport pattern (figures 6a and 8a). This indicates similar offshore sediment transport magnitudes onshore of the bar which are caused by the dominant influence of the undertow. This confirms the results of previous studies, such as $[2,12,15]$, where the influence of the breaking location with its resulting undertow on the bar location was shown to be important. 


\subsection{Accretive wave conditions}

The results presented in this study provide further evidence of the different evolution of breaker bars under accretive wave conditions compared to erosive wave conditions. For breaker bar evolution under accretive wave conditions, the beach morphology and its feedback with the wave conditions is found to have an important impact. In WISE 1 and WISE 2, the morphology before the start of the accretive wave conditions was the same but the bar evolution was different and therefore, the differences in wave conditions evidently cause differences in bar evolution.

It is postulated that a stronger reduction of $\Omega$ from erosive to accretive wave conditions (as in WISE 2 and also as in SANDS) is more likely to result in the decay of the bar. In contrast, a smaller reduction $\Omega$ (as in WISE 1) is more likely to result in an entirely shoreward migrating bar. This can be described in a quantitative way by computing the reduction of $\Omega$ from erosive to accretive wave conditions as $\Delta \Omega=\Omega_{\text {erosive }}-\Omega_{\text {accretive }}$. $\Delta \Omega$ was $2.04,1.74$ and 2.24 for SANDS, WISE 1 and WISE 2 , respectively. Other studies $[23,35]$ have postulated similar relationships expressing $\Delta \Omega$ as the deviation of $\Omega$ with respect to an equilibrium value $\Omega_{e}$. However, the definition of $\Omega_{e}$ is not clear in an experimental context. Because $\Omega_{\text {erosive }}$ does not account for the duration of the erosive wave conditions, $\Omega_{\text {erosive }}$ is considered to have resulted in a quasi-equilibrium beach profile but it is noted that full equilibrium conditions would most likely take much longer. The values of $\Delta \Omega$ show that a larger $\Delta \Omega$ of $>2.00$ as in SANDS and WISE 2 is linked to a decaying bar whereas a lower reduction of $\Omega$ results in a bar that migrates onshore as a whole. The change in $\Omega$ relates the morphology 
obtained under erosive wave conditions to the accretive wave conditions.

The importance of the feedback between the morphology and the accretive wave conditions on the bar evolution pattern is shown by the change of the wave breaking location with the morphological change of the bar. For an intertidal bar, Houser and Greenwood [10] already pointed out the importance of the bar height for the wave breaking location. Ruessink and Terwindt [46] postulated that the decay process of a bar is crucial for the continuation of a bar cycle. In case of a decaying outer bar, the breakpoint shifts to the inner bar where now surf conditions dominate. This may cause initiation of offshore migration of the inner bar and has been similarly observed in recent medium-scale morphodynamic experiments presented by Baldock et al. [35].

Figure 13 illustrates the change of the wave breaking location (vertical dashed-dotted lines) with respect to the bar location (vertical solid lines) during the changing bar morphology for SANDS, WISE 1 and WISE 2. The procedure to obtain the breaking location was explained in section 3. Left panels show the first profile obtained under accretive wave conditions and the corresponding $H_{s}$ and $\gamma$ at the time instant where the bar is still almost as fully evolved as under erosive wave conditions. Right panels show the profiles and the corresponding $H_{s}$ and $\gamma$ after $525 \mathrm{~min}$ in SANDS and after $360 \mathrm{~min}$ in WISE 1 and WISE 2 where the water depth was maximum in SANDS and WISE 2 due to the decayed bar (see figure 5b). A general reduction of $H_{s}$ after primary wave breaking is observed in figure 13 .

In SANDS, a clear influence of the changing bar morphology on the location of wave breaking can be noted. At the beginning of the accretive wave 
conditions, wave breaking occurs slightly onshore of the bar location (figure 13a). As shown in figure 7a, offshore sediment transport is too weak to prevent the bar from decaying during its initial onshore migration. Once the bar has reduced its height and has migrated onshore, the breakpoint is found further onshore of the bar location (figure 13b). As also shown in Baldock et al. [35, figure 11], the change of the breakpoint with respect to the bar location suggests that the decreased bar height makes the breakpoint move onshore into shallower water where $\gamma$ reaches a similar value at which wave breaking occurs. For SANDS, it is assumed that this interaction of breakpoint and bar location is very clearly pronounced because the bar is large in scale, relatively far offshore and covers a large cross-shore area compared to the bars in WISE 1 and WISE 2.

In WISE 1 the bar reduces its height only slightly compared to the other data and the breakpoint is consistently found offshore of the bar location (figure $13 \mathrm{c}$ and $13 \mathrm{~d}$ ). In WISE 2 , at the beginning of the accretive wave conditions (figure 13e), the profile is still similar to WISE 1 and the breakpoint is found at a similar location offshore of the bar. Because wave conditions were more accretive in WISE 2 offshore sediment transport onshore of the bar was weaker shown in figures $6 \mathrm{~b}, 7 \mathrm{c}$ and $8 \mathrm{~b}$. As the bar decays, the breakpoint changes to a location slightly onshore of the bar (figure 13f).

Figure 13 shows that the feedback between the morphology and the wave conditions is important for the evolution of both an almost non-decaying and a decaying breaker bar. This feedback can lead to a very similar bar evolution pattern despite different wave conditions and different beach morphologies as in SANDS and WISE 2. Even though wave conditions were less accretive 
in $\operatorname{SANDS}(\Omega=1.73)$ than in WISE $2(\Omega=1.50)$, the offshore sediment transport in SANDS is not strong enough to prevent the larger and further offshore located bar from decaying.

In the presented analysis it must be considered that the bar location is only described by a single value corresponding to the location of maximum profile elevation. Especially under accretive wave conditions, particularly in case of a decaying bar, a bar often extends over a certain cross-shore distance which is not captured by describing the bar location by one single value. In addition, the spatial accuracy for the definition of the breakpoint depends on the resolution of the water surface elevation data from which the breakpoint is defined. This resolution is usually ca. 1-2 $\mathrm{m}$ in the surf zone. The change of the breakpoint with the changing morphology potentially occurs on a smaller spatial scale which cannot be captured by the resolution of the water surface elevation data in large-scale experiments.

The feedback between the morphology and the wave conditions is also suggested to be important for the differences in the bar dynamics between the other data sets (figure 12d). However, a more detailed comparison, including hydrodynamic data, would be required for a more detailed investigation.

\section{Conclusions}

The present study reveals that important differences between breaker bar evolution under erosive and accretive wave conditions exist under experimental conditions. While under erosive wave conditions breaker bars exhibit a clear linear relationship between the bar height and the bar location, breaker bar evolution under accretive wave conditions cannot be described by a single 

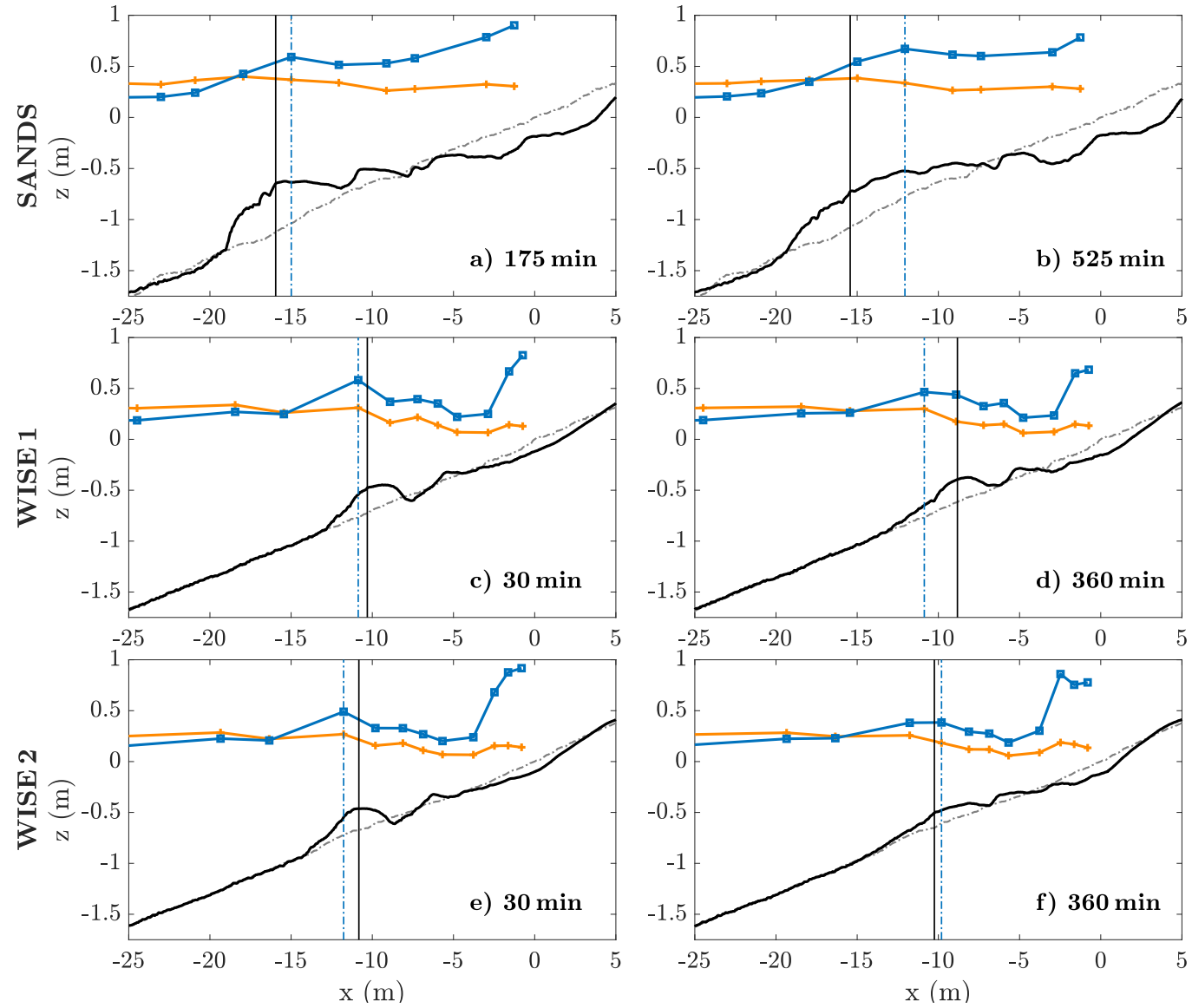

Figure 13: Change of breakpoint with respect to the bar location during changing morphology under accretive wave conditions; initial profile $(-\cdot-)$, profile after indicated time ( $\longrightarrow$ ), wave height $H_{s}(-)$ ), relative wave height $\gamma(\square)$, breaking location $(-\cdot-)$, bar location $(-)$

pattern.

The three primarily studied data sets from the CIEM showed that, under erosive wave conditions, breaker bars are driven by the energetic conditions of the waves and the resulting breaking location. This strong influence of 
the wave conditions on the bar evolution resulted in a very similar crossshore sediment transport pattern and allowed to develop a simple model to reproduce beach profiles based on the wave breaking location. The model reproduces the beach profiles well and is, in its present form, most likely specific for the wave flume, the sediment characterstics and the beach slope.

Under accretive wave conditions, the breaker bars from the three CIEM experiments were found to either migrate onshore as a whole (non-decaying bar) or to reduce their height during onshore migration and potentially regrow further onshore (decaying bar). These two bar migration patterns depend on the feedback between beach morphology and the wave conditions. A larger reduction of the energetic conditions from erosive to accretive wave conditions was shown to result in a decaying bar because of the relatively weak offshore sediment transport onshore of the bar. Once the bar has decayed, the breaking location moves onshore which results in increased (reduced) offshore (onshore) sediment transport onshore (offshore) of the bar potentially triggering the recovery of the bar.

The three data sets were compared against numerous experimental beach profile data obtained in large-scale wave flumes around the world. These data support that the bar height changes linearly with the bar location under erosive wave conditions. The two breaker bar evolution patterns under accretive wave conditions, which were found for the three data sets from the CIEM, are not perfectly supported by the limited number of other data sets. This encourages the performance of further large-scale experiments on breaker bar morphodynamics, especially under accretive wave conditions. 


\section{Acknowledgements}

The experimental part of this work was supported by EC research projects HYDRALAB IV (Contract no. 261520) and Hydralab-III SANDS Project (contract number: 022441) (RII3). The first author acknowledges the PhD funding from the Department of Civil and Environmental Engineering, Imperial College London. We would like to thank Professor Tom Baldock and one anonymous reviewer for their comments that helped to improve the manuscript. 


\section{References}

[1] E. L. Gallagher, S. Elgar, R. T. Guza, Observations of sand bar evolution on a natural beach, Journal of Geophysical Research 103 (1998) 32033215.

[2] F. Hoefel, S. Elgar, Wave-induced sediment transport and sandbar migration, Science 299 (5614) (2003) 1885-1887.

[3] L. C. Van Rijn, P. K. Tonnon, D. J. R. Walstra, Numerical modelling of erosion and accretion of plane sloping beaches at different scales, Coastal Engineering 58 (7) (2011) 637-655.

[4] A. Fernández-Mora, D. Calvete, A. Falqués, H. E. de Swart, Onshore sandbar migration in the surf zone: New insights into the wave induced sediment transport mechanisms, Geophysical Research Letters 1 (42) (2015) 2869-2877.

[5] S. M. Henderson, J. S. Allen, P. A. Newberger, Nearshore sandbar migration predicted by an eddy-diffusive boundary layer model, Journal of Geophysical Research 109 (6) (2004) 1-15.

[6] S. Falchetti, D. C. Conley, M. Brocchini, S. Elgar, Nearshore bar migration and sediment-induced buoyancy effects, Continental Shelf Research 30 (2) (2010) 226-238.

[7] T. J. Hsu, S. Elgar, R. T. Guza, Wave-induced sediment transport and onshore sandbar migration, Coastal Engineering 53 (10) (2006) 817-824. 
[8] B. Dubarbier, B. Castelle, V. Marieu, G. Ruessink, Process-based modeling of cross-shore sandbar behavior, Coastal Engineering 95 (2015) $35-50$.

[9] B. van Maanen, P. J. de Ruiter, G. Coco, K. R. Bryan, B. G. Ruessink, Onshore sandbar migration at Tairua Beach (New Zealand): Numerical simulations and field measurements, Marine Geology 253 (3-4) (2008) 99-106.

[10] C. Houser, B. Greenwood, Onshore Migration of a Swash Bar During a Storm, Journal of Coastal Research 231 (2007) 1-14.

[11] G. Masselink, A. Kroon, R. G. D. Davidson-Arnott, Morphodynamics of intertidal bars in wave-dominated coastal settings - A review, Geomorphology 73 (1-2) (2006) 33-49.

[12] I. J. Mariño-Tapia, P. E. Russell, T. J. O'Hare, M. A. Davidson, D. A. Huntley, Cross-shore sediment transport on natural beaches and its relation to sandbar migration patterns: 1 . Field observations and derivation of a transport parameterization, Journal of Geophysical Research: Oceans 112 (3) (2007) 1-15.

[13] J. Roelvink, M. Stive, Bar-Generating Cross-Shore Flow Mechanisms on a Beach, Journal of Geophysical Research 94 (C4) (1989) 4785-4800.

[14] N. G. Plant, R. a. Holman, M. H. Freilich, W. a. Birkemeier, A simple model for interannual sandbar behavior, Journal of Geophysical Research 104 (C7) (1999) 15755-15776. 
[15] I. J. Mariño-Tapia, P. E. Russell, T. J. O’Hare, M. A. Davidson, D. A. Huntley, Cross-shore sediment transport on natural beaches and its relation to sandbar migration patterns: 2. Application of the field transport parameterization, Journal of Geophysical Research: Oceans 112 (3) (2007) 1-12.

[16] S. Costas, O. Ferreira, G. Martinez, Why do we decide to live with risk at the coast?, Ocean and Coastal Management 118 (2015) 1-11.

[17] K. D. Splinter, J. T. Carley, A. Golshani, R. Tomlinson, A relationship to describe the cumulative impact of storm clusters on beach erosion, Coastal Engineering 83 (2014) 49-55.

[18] H. Karunarathna, D. Pender, R. Ranasinghe, A. D. Short, D. E. Reeve, The effects of storm clustering on beach profile variability, Marine Geology 348 (2014) 103-112.

[19] G. Coco, N. Senechal, A. Rejas, K. R. Bryan, S. Capo, J. P. Parisot, J. A. Brown, J. H. M. MacMahan, Beach response to a sequence of extreme storms, Geomorphology 204 (2014) 493-501.

[20] Ó. Ferreira, Storm Groups versus Extreme Single Storms: Predicted Erosion and Management Consequences, Journal of Coastal Research 42 (2005) 221-227.

[21] J. M. Alsina, I. Cáceres, Sediment suspension events in the inner surf and swash zone. Measurements in large-scale and high-energy wave conditions, Coastal Engineering 58 (8) (2011) 657-670. 
[22] A. Sánchez-Arcilla, I. Cáceres, An analysis of nearshore profile and bar development under large scale erosive and accretive waves, Journal of Hydraulic Research (2017) 1-14.

[23] T. E. Baldock, J. M. Alsina, I. Caceres, D. Vicinanza, P. Contestabile, H. Power, A. Sanchez-Arcilla, Large-scale experiments on beach profile evolution and surf and swash zone sediment transport induced by long waves, wave groups and random waves, Coastal Engineering 58 (2) (2011) 214-227.

[24] D. A. Van der A, T. O'Donoghue, A. G. Davies, J. S. Ribberink, Experimental study of the turbulent boundary layer in acceleration-skewed oscillatory flow, Journal of Fluid Mechanics 684 (2011) 251-283.

[25] R. G. Dean, Heuristic Models of Sand Transport in the Surf Zone, Proceedings of Conference on Engineering Dynamics in the Surf Zone, Sydney (1973) 208-214.

[26] J. M. Alsina, E. M. Padilla, I. Cáceres, Sediment transport and beach profile evolution induced by bi-chromatic wave groups with different group periods, Coastal Engineering 114 (2016) 325-340.

[27] H. E. Power, M. G. Hughes, T. Aagaard, T. E. Baldock, Nearshore wave height variation in unsaturated surf, Journal of Geophysical Research: Oceans 115 (8) (2010) 1-15.

[28] E. M. Padilla, J. M. Alsina, Transfer and dissipation of energy during wave group propagation on a gentle beach slope, Journal of Geophysical Research (2017) 6773-6794. 
[29] J. M. Alsina, I. Cáceres, M. Brocchini, T. E. Baldock, An experimental study on sediment transport and bed evolution under different swash zone morphological conditions, Coastal Engineering 68 (2012) 31-43.

[30] P. E. Russell, D. A. Huntley, A cross-shore transport 'shape function' for high energy beaches, Journal of Coastal Research 15 (1) (1999) 198-205.

[31] R. A. Bagnold, The flow of cohesionless grains in fluids, Philosophical Transactions Of The Royal Society Of London Series A 249 (964) (1956) 235-297.

[32] R. A. Bagnold, Mechanics of Marine Sedimentation, in: M. N. Hill (Ed.), The Sea: Ideas and Observations on progress in the study of the seas, volume 3 Edition, Wiley-Interscience, London, 1963, Ch. Beach and, pp. $207-528$.

[33] I. Cáceres, J. M. Alsina, A detailed, event-by-event analysis of suspended sediment concentration in the swash zone, Continental Shelf Research 41 (2012) 61-76.

[34] D. G. Goring, V. I. Nikora, Despiking Acoustic Doppler Velocimeter Data, Journal of Hydraulic Engineering 128 (1) (2002) 117-126.

[35] T. Baldock, F. Birrien, A. Atkinson, T. Shimamoto, S. Wu, D. Callaghan, P. Nielsen, Morphological hysteresis in the evolution of beach profiles under sequences of wave climates - Part 1; observations, Coastal Engineering 128 (2017) 92-105.

[36] A. Sánchez-Arcilla, I. Cáceres, L. van Rijn, J. Grüne, Revisiting mobile 
bed tests for beach profile dynamics, Coastal Engineering 58 (7) (2011) 583-593.

[37] B. G. Ruessink, A. Kroon, The behaviour of a multiple bar system in the nearshore zone of Terschelling, the Netherlands: 1965-1993, Marine Geology 121 (1992) (1994) 187-197.

[38] K. M. Wijnberg, On the systematic offshore decay of breaker bars, in: 25th International Conference on Coastal Engineering, 1996, pp. 36003613.

[39] L. C. van Rijn, D. J. R. Wasltra, B. Grasmeijer, J. Sutherland, S. Pan, J. P. Sierra, The predictability of cross-shore bed evolution of sandy beaches at the time scale of storms and seasons using process-based profile models, Coastal Engineering 47 (3) (2003) 295-327.

[40] A. S.-Arcilla, J. A. Roelvink, B. A. O'Connor, A. Reniers, J. A. Jiménez, The Delta Flume'93 Experiment, in: Coastal Dynamics '94, ASCE, 1994, pp. 488-502.

[41] I. Cáceres, J. Grüne, L. Van Rijn, S.-A. Agustín, A. Ahmari, J. Ribberink, Mobile-bed Tests. The Sands Project. (2008) 2622-2632.

[42] H. H. Dette, M. Larson, J. Murphy, J. Newe, K. Peters, A. Reniers, H. Steetzel, Application of prototype flume tests for beach nourishment assessment, Coastal Engineering 47 (2) (2002) 137-177.

[43] T. Shimizu, M. Ikeno, Experimental Study on Sediment Transport in Surf and Swash Zones Using Large Wave Flume, in: 25th International Conference on Coastal Engineering, 1996, pp. 3076-3089. 
[44] H. D. Yoon, D. T. Cox, Large-scale laboratory observations of wave breaking turbulence over an evolving beach, Journal of Geophysical Research: Oceans 115 (10) (2010) 1-16.

[45] N. C. Kraus, J. McKee Smith, C. K. Sollitt, Supertank Laboratory Data Collection Project, in: 23rd International Conference on Coastal Engineering, 1994, pp. 2191-2204.

[46] B. G. Ruessink, J. H. Terwindt, The behaviour of nearshore bars on the time scale of years: A conceptual model, Marine Geology 163 (1-4) (2000) 289-302. 